\title{
Undergraduate Students' Perception on Assessment Experience in a Malaysian Medical School: Comparison among Gender, Ethnicity and Phase of Study
}

\author{
Mazlan NA ${ }^{a}$, Selvakumar $\mathrm{S}^{a}, \mathrm{Teh} \mathrm{XH}^{a}$, Idris $\mathrm{F}^{b, c}$, Adam SK $^{b, d, *}$ \\ ${ }^{a}$ Doctor of Medicine (MD) programme, Faculty of Medicine and Health Sciences, Universiti Putra Malaysia, 43400 UPM Serdang, Selangor, Malaysia \\ ${ }^{b}$ Medical Education Research and Innovation Unit, Faculty of Medicine and Health Sciences, Universiti Putra Malaysia, 43400 UPM Serdang, Selangor, \\ Malaysia \\ ${ }^{c}$ Department of Pathology, Faculty of Medicine and Health Sciences, Universiti Putra Malaysia, 43400 UPM Serdang, Selangor, Malaysia \\ ${ }^{d}$ Department of Human Anatomy, Faculty of Medicine and Health Sciences, Universiti Putra Malaysia, 43400 UPM Serdang, Selangor, Malaysia
}

\section{ABSTRACT}

Keywords

assessment, Assessment Experience

Questionnaire, ethnicity, gender, learning

Corresponding Author

Siti Khadijah Adam, PhD

Medical Education Research and Innovation

Unit \&

Department of Human Anatomy

Faculty of Medicine and Health Sciences,

Universiti Putra Malaysia,

43400 UPM Serdang,

Selangor, Malaysia.

Tel: +603-97692354

Email: sk.adam@upm.edu.my

Received: 28 September 2020 ; Accepted: 6 April 2021

Doi: https://doi.org/10.31436/imjm.v20i3
INTRODUCTION: It is a well-known fact that assessment influences learning and study behaviour. Assessment affects what and how students learn, either positive or negative learning behaviour. This study was aimed to determine students' perceived assessment experience and the comparison among different gender, ethnicity, and phase of the study.

MATERIALS AND METHODS: This is a cross-sectional study. Assessment Experience Questionnaire (AEQ) version 3.3 was distributed to 324 undergraduate medical students of Universiti Putra Malaysia. The AEQ score among different gender, ethnicity, and phase of the study was compared using independent t-test and one-way ANOVA. RESULTS: Female students were found to develop a surface approach to learning, learn new things from the assessment, and be satisfied more with the teaching compared to males. Chinese students tended to put higher effort into learning compared to Malay. Clinical students valued more the feedback received and had clearer goals and expectations for their work than preclinical students. However, preclinical students tended to put a higher quantity of effort, learn wider coverage of syllabus and develop a surface approach of learning than clinical students. The respondents commented that feedback is lacking and suggested having more feedback sessions with their teachers after assessment. CONCLUSION: There were different assessment experiences and learning found among different gender, race, and phase of the study. These may affect their academic performance and are probably due to the curriculum setting. Understanding student assessment experience and its impact helps the faculty to improve the assessment structure for a conducive assessment environment and meaningful learning experience for the students.

\section{INTRODUCTION}

Assessment is the process of evaluating the level of the learner's knowledge, skills, and attitude. The purpose is to make judgement and decisions on student's learning against a certain standard. ${ }^{1}$ It is mainly used to assess and evaluate whether students have achieved the learning outcomes throughout the study. Ultimately, it is an integral part of medical education to certify safe and competent doctors who can serve the public.

Assessment can be categorised into formative assessments and summative assessments. Formative assessment takes place throughout teaching and learning. It is employed primarily to provide feedback to the learners' performance, guide their learning process to improve their performance as preparation prior to summative assessment. On the other hand, summative assessment usually takes place at the tip of a term or a course. It is used to supply data to make a judgement on learners' performance and usually has major consequences to the learners. In Malaysia, particularly in Universiti Putra Malaysia (UPM), the assessments for medical students are both formative and summative. 
While formative assessment is conducted continuously, summative assessment is considered dominant which highly focuses on grades to determine learner's progress. Additionally, the assessment in the preclinical phase emphasises theoretical knowledge whereas the clinical phases emphasises clinical performance.

It is a well-known fact that assessment is closely related to learning. What and how students learn largely depends on what and how they are being assessed. ${ }^{2}$ For example, a previous study was done on undergraduate medical students has found that the anxiety of summative assessment led to a surface approach to learning. ${ }^{3}$ This is supported by another recent study which found that students tended to only practise memorising the knowledge without understanding it to pass the summative examination. ${ }^{4}$ Based on pieces of literature, several factors contribute to the differences of learning behaviour which would be affecting their academic performance. With regards to gender, female students were found to be outperformed compared to males because they were more hardworking, dedicated, and highly ambitious in the studies. ${ }^{5}$ In another local study in 2015 has found that female students managed to score well in English writing by applying the surface approach of learning. ${ }^{6}$ Moreover, our earlier study in UPM has found that the academic phase of the study was associated with learning approaches. ${ }^{7} \mathrm{We}$ found that majority of the clinical students adopted a deep approach to learning. This, however, was in contrast with a study involving medical students in Sri Lanka which highlighted that the students were prone to have superficial learning due to the excessive workload which might favour the assessments. ${ }^{8}$

Previous studies have shown that there was a discrepancy between the achievement level of different ethnicities. Specifically in medical education, White students were found to perform better compared to other ethnic minority students.9,10 This may be attributed to the lower level of the social capital in the minority group that compromised their learning. This may influence their learning behaviour and subsequently, academic achievement among different ethnicities.

In 2003, Gibbs and Simpson have developed the Assessment Experience Questionnaire (AEQ) which focuses on how assessment influenced learning. ${ }^{11}$ AEQ is used to evaluate the effectiveness of an assessment system to influence student's learning and to be able to improve that assessment. Based on their study, there are several conditions for assessment to support student learning. The conditions were grouped under five headings; (i) quantity and distribution of student effort, (ii) quality and level of student effort, (iii) quantity and timing of feedback, (iv) quality of feedback, and (v) student response to feedback. ${ }^{11}$ These conditions have provided a conceptual framework to see how well an assessment supports student's learning. Therefore, a deductive approach is used in this study to determine the perceived experience among UPM undergraduate medical students on the assessment. This study also aimed to investigate whether different gender, race, and academic phases were associated with different assessment experiences and learning. Feedback and suggestions regarding current assessment practice from UPM undergraduate medical students were gathered to support the improvement of the current assessment practice.

\section{MATERIALS AND METHODS}

\section{Study setting}

A cross-sectional study was carried out in the UPM undergraduate Doctor of Medicine (MD) program from April 2019 to August 2019. The program has about 100 students per cohort and is divided into two phases, namely preclinical and clinical. Each phase runs for 2 and 3 years, respectively. For the preclinical phase, the mid-course assessment consists of written tests, seminar presentations, and laboratory reports which contribute $15 \%$ to the total score of the course. The final examination is divided into theory and practical examinations. Multiple-choice questions (MCQs) and short answer questions (SAQs) are examples of theory examination while objective structured practical examination (OSPE) and objective structured clinical examination (OSCE) are for practical examination. The students are required to submit their research dissertation and must pass the end of the preclinical phase examination to proceed to the clinical phase. The students also are required to conduct a research project and complete a research dissertation. At the end of the preclinical phase, they must pass the Professional 1 
Examination to progress to the clinical phase.

For the clinical phase, the students are divided into smaller groups in each clinical posting and are required to complete their logbook which includes documenting the patients and cases they encounter, attend seminar presentations, and submit written assignments such as case write-up. They are assessed at the end of each posting written and clinical examinations such as MCQs, modified essay questions (MEQs), OSCE, long case, and short case examinations depending on the posting. In the final year, they must pass the end-ofphase Professional 2 Examination to be awarded the degree. Throughout the program, lecturers and/or academic advisors are encouraged to provide feedback to the students. Students who do not achieve the minimum passing mark need to undergo remediation to progress to the next phase.

\section{Participants}

The study involved Year 1 to Year 5 MD students in the $2018 / 2019$ academic session $(n=500)$. A total of 388 students were required based on the sample size formula for two independent groups ${ }^{12}$ and a proportionate stratified random sampling technique was used to determine the number of students from each year. The name list was obtained from the academic office of the faculty. The participants were explained about the purpose of the study and their confidentiality was ensured by not recording their identity during the data collection. Written consent was obtained and only consented students were invited to participate in the study. The ethical approval for this study was obtained from the Ethics Committee for Research Involving Human Subjects UPM (Reference no: UPM/TNCPI/ RMC/JKEUPM/1.4.18.2).

\section{Questionnaire}

A self-administered questionnaire was used to characterise students' assessment experiences. The questionnaire consisted of 3 parts, demographic characteristics (race, gender, year of study), AEQ version 3.311, and student's feedback and suggestion regarding current assessment practice. The AEQ contains 28 individual items which form 10 domains i.e. quantity of effort, coverage of syllabus, quantity, and quality of feedback, use of feedback, appropriate assessment, clear goals and standards, surface approach, deep approach, learning from the examination, and satisfaction. The participants were required to respond to each item from a five-point Likert scale (strongly disagree, disagree, neutral, agree, strongly agree). These responses were converted into numeric, 1 for strongly disagree while 5 for strongly agree. The negative statements i.e. statements $3,5,10,11,12,14,15,16$, and 18 , were scored in reverse so that the higher the score, the stronger the agreement with the statement. The average score for each scale was calculated and analysed using IBM SPSS software version 25. All data were normally distributed, therefore independent t-test and one-way ANOVA (Bonferroni post-hoc test) tests were conducted to identify the factors associated with the participants' perceived assessment experience.

The later part of the questionnaire was to obtain narrative feedback and suggestions on the current assessment practice in UPM. They were allowed to express their suggestions, opinion, and recommendations regarding the use of assessment and the ways to improve the assessment system.

\section{RESULTS}

A total of 324 participants had participated, yielding a response rate of $83.5 \%$. The demographic characteristics of the respondents are summarised in Table I. Majority of the respondents were female and from Malay ethnicity. The number of preclinical and clinical students was almost equal.

Generally, the perception of respondents on their assessment ranging from neutral to strongly agree in all AEQ domains depicted by the average total score (Table II).

Table I: Demographic characteristics of the respondents $(n=324)$

\begin{tabular}{lc}
\hline Characteristics & $\begin{array}{c}\text { Frequency } \\
\mathbf{n}(\%)\end{array}$ \\
\hline Gender & $97(29.9)$ \\
Male & $227(70.1)$ \\
Female & \\
Race & $182(56.2)$ \\
Malay & $75(23.1)$ \\
Chinese & $61(18.8)$ \\
Indian & $6(1.9)$ \\
Others & \\
Academic & \\
phase & $167(51.5)$ \\
Preclinical & $157(48.5)$ \\
Clinical &
\end{tabular}

IMJM Volume 20 No.3, July 2021 
The highest score was found in the 'deep approach' domain, followed by 'quantity of effort' and 'learning from examination' domains. This suggests that UPM medical students tended to develop deep approaches to learning and put high effort to fulfil their assessment demands. Moreover, the assessment encouraged them to learn new things. However, the respondents showed the least agreement on the quantity and quality of feedback received after every learning task indicated by the lowest average score of the corresponding domain.

The comparison of students' perception on assessment experience between gender is presented in Table II. There was a significant association of gender in three AEQ domains. Female respondents were found to develop a surface approach of learning, learn new things from the assessment, and be satisfied more with the teaching compared to male respondents. Additionally, the comparison among different ethnicities was also determined. There was no significant difference observed among the ethnicities in all AEQ domains, except the quantity of effort and surface approach domain (Table III). The post-hoc analysis found that the Chinese tended to put higher effort into learning as compared to Malay.

The comparison of students' perception of assessment experience between the preclinical and clinical phases of the study is presented in Table IV. It can be observed that the average AEQ scores in clinical students were higher in the 'use of feedback' and 'clear goals and standards' domains. This implies that clinical students valued more the feedback received in their learning and had clearer goals and expectations from their teachers on their work than preclinical students. However, their AEQ scores were significantly lower than preclinical students in the 'quantity of effort', 'coverage of syllabus', 'appropriate assessment', and 'surface approach' domains. The clinical students seemed to have less agreement that their assessment questions were appropriate than preclinical students.

Table II: Average score of assessment experience questionnaire domains for all respondents $(\mathrm{n}=324)$ and the comparison between gender.

\begin{tabular}{|c|c|c|c|c|c|c|}
\hline \multirow[b]{2}{*}{ AEQ domain } & \multicolumn{3}{|c|}{ Mean (SD) } & \multirow{2}{*}{$\begin{array}{l}\text { Mean difference } \\
(95 \% \mathrm{CI})\end{array}$} & \multirow{2}{*}{$\begin{array}{l}\text { t-statistic } \\
(\mathrm{df}=322)\end{array}$} & \multirow[b]{2}{*}{ p-value } \\
\hline & Total & $\begin{array}{c}\text { Male } \\
(n=97)\end{array}$ & $\begin{array}{l}\text { Female } \\
(n=227)\end{array}$ & & & \\
\hline Quantity of effort & $3.99(0.67)$ & $3.90(0.69)$ & $4.03(0.66)$ & $\begin{array}{c}-0.127 \\
(-0.286,0.033)\end{array}$ & -1.564 & 0.119 \\
\hline Coverage of syllabus & $3.72(0.54)$ & $3.72(0.57)$ & $3.72(0.53)$ & $\begin{array}{c}0.002 \\
(-0.127,0.132)\end{array}$ & 0.038 & 0.970 \\
\hline $\begin{array}{l}\text { Quantity and quality of } \\
\text { feedback }\end{array}$ & $3.15(0.66)$ & $3.21(0.72)$ & $3.12(0.63)$ & $\begin{array}{c}0.092 \\
(-0.065,0.249)\end{array}$ & 1.155 & 0.249 \\
\hline Use of feedback & $3.59(0.74)$ & $3.50(0.78)$ & $3.63(0.72)$ & $\begin{array}{c}-0.127 \\
(-0.303,0.049)\end{array}$ & -1.424 & 0.155 \\
\hline Appropriate assessment & $3.49(0.72)$ & $3.54(0.79)$ & $3.47(0.69)$ & $\begin{array}{c}0.075 \\
(-0.097,0.246)\end{array}$ & 0.855 & 0.393 \\
\hline Clear goals and standards & $3.20(0.54)$ & $3.19(0.58)$ & $3.20(0.53)$ & $\begin{array}{c}-0.009 \\
(-0.139,0.121)\end{array}$ & -0.140 & 0.889 \\
\hline Surface approach & $3.83(0.67)$ & $3.68(0.75)$ & $3.90(0.63)$ & $\begin{array}{c}-0.215 \\
(-0.373,-0.056)\end{array}$ & -2.664 & $0.008^{*}$ \\
\hline Deep approach & $4.02(0.65)$ & $3.94(0.65)$ & $4.06(0.65)$ & $\begin{array}{c}-0.118 \\
(-0.273,0.037)\end{array}$ & -1.493 & 0.136 \\
\hline $\begin{array}{l}\text { Learning from the } \\
\text { examination }\end{array}$ & $3.96(0.70)$ & $3.83(0.73)$ & $4.01(0.68)$ & $\begin{array}{c}-0.184 \\
(-0.349,-0.019)\end{array}$ & -2.188 & $0.029 *$ \\
\hline Satisfaction & $3.73(0.64)$ & $3.58(0.67)$ & $3.79(0.62)$ & $\begin{array}{c}-0.204 \\
(-0.356,-0.052)\end{array}$ & -2.638 & $0.009 *$ \\
\hline
\end{tabular}

a independent t-test, $* p<0.05$ 
Table III: Comparison of the score of assessment experience questionnaire domains among Malay ( $\mathrm{n}=182)$, Chinese ( $\mathrm{n}=75)$, Indian ( $\mathrm{n}=61)$ and others $(\mathrm{n}=6)$

\begin{tabular}{|c|c|c|c|c|}
\hline AEQ domain & & & $F$-statistic & $p$-value ${ }^{a}$ \\
\hline \multirow{5}{*}{ Quantity of effort } & Malay & $3.92(0.68)$ & \multirow{5}{*}{2.965} & \multirow{5}{*}{$0.032^{* \#}$} \\
\hline & Chinese & $4.18(0.62)$ & & \\
\hline & & & & \\
\hline & Indian & $3.96(0.68)$ & & \\
\hline & Others & $4.17(0.52)$ & & \\
\hline \multirow{5}{*}{ Coverage of syllabus } & Malay & $3.73(0.54)$ & \multirow{5}{*}{1.529} & \multirow{5}{*}{0.207} \\
\hline & Chinese & $3.79(0.48)$ & & \\
\hline & 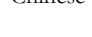 & & & \\
\hline & Indian & $3.59(0.60)$ & & \\
\hline & Others & $3.71(0.49)$ & & \\
\hline \multirow{5}{*}{ Quantity and quality of feedback } & Malay & $3.17(0.58)$ & \multirow{5}{*}{1.147} & \multirow{5}{*}{0.330} \\
\hline & Chinese & $3.14(0.79)$ & & \\
\hline & & & & \\
\hline & Indian & $3.13(0.70)$ & & \\
\hline & Others & $2.67(0.60)$ & & \\
\hline \multirow{5}{*}{ Use of feedback } & Malay & $3.61(0.68)$ & \multirow{5}{*}{1.885} & \multirow{5}{*}{0.132} \\
\hline & Chinese & $3.67(0.83)$ & & \\
\hline & & & & \\
\hline & Indian & $3.39(0.78)$ & & \\
\hline & Others & $3.72(0.39)$ & & \\
\hline \multirow{5}{*}{ Appropriate assessment } & Malay & $3.52(0.67)$ & \multirow{5}{*}{1.498} & \multirow{5}{*}{0.215} \\
\hline & Chinese & $3.43(0.79)$ & & \\
\hline & & & & \\
\hline & Indian & $3.53(0.76)$ & & \\
\hline & Others & $2.94(0.83)$ & & \\
\hline \multirow{4}{*}{ Clear goals and standards } & Malay & $3.25(0.50)$ & \multirow{4}{*}{2.607} & \multirow{4}{*}{0.052} \\
\hline & Chinese & $3.09(0.59$ & & \\
\hline & Indian & $3.12(0.58)$ & & \\
\hline & Others & $3.50(0.46)$ & & \\
\hline \multirow{5}{*}{ Surface approach } & Malay & $3.92(0.64)$ & \multirow{5}{*}{2.764} & \multirow{5}{*}{$0.042 *$} \\
\hline & Chinese & $3.78(0.60)$ & & \\
\hline & & & & \\
\hline & Indian & $3.69(0.80)$ & & \\
\hline & Others & $3.44(0.54)$ & & \\
\hline \multirow{5}{*}{ Deep approach } & Malay & $4.03(0.64)$ & & \\
\hline & Chinese & $4.03(0.66$ & & \\
\hline & Jodian & $398(070)$ & 0.195 & 0.900 \\
\hline & & & & \\
\hline & Others & $4.17(0.28)$ & & \\
\hline & Malay & $3.92(0.72)$ & & \\
\hline & Chinese & $4.05(0.69)$ & & \\
\hline Learning from the examination & & & 0.628 & 0.597 \\
\hline & Indian & $3.95(0.66)$ & & \\
\hline & Others & $3.83(0.51)$ & & \\
\hline & Malay & $3.76(0.64)$ & & \\
\hline & Chinese & $3.76(0.68)$ & & \\
\hline Satisfaction & & & 2.354 & 0.072 \\
\hline & Indian & $3.54(0.61)$ & & \\
\hline & Others & $4.00(0.32)$ & & \\
\hline
\end{tabular}

One-way ANOVA, $* p<0.05$, \#Post-hoc analysis with Tukey HSD shows significant difference between Chinese and Malay $(p=0.22)$ 
Table IV: Comparison of the score of assessment experience questionnaire domains between the phase of the study

\begin{tabular}{|c|c|c|c|c|c|}
\hline \multirow[b]{2}{*}{ AEQ scale } & \multicolumn{2}{|c|}{ Mean (SD) } & \multirow[b]{2}{*}{$\begin{array}{l}\text { Mean difference } \\
\qquad(95 \% \mathrm{CI})\end{array}$} & \multirow[b]{2}{*}{$\begin{array}{l}\text { t-statistic } \\
(\mathrm{df}=322)\end{array}$} & \multirow[b]{2}{*}{ p-value ${ }^{a}$} \\
\hline & $\begin{array}{c}\text { Preclinical } \\
(n=167)\end{array}$ & $\begin{array}{l}\text { Clinical } \\
(n=157)\end{array}$ & & & \\
\hline Quantity of effort & $4.12(0.63)$ & $3.85(0.69)$ & $0.266(0.123,0.410)$ & 3.649 & $<0.001 *$ \\
\hline Coverage of syllabus & $3.99(0.55)$ & $3.65(0.53)$ & $0.140(0.217,0.257)$ & 2.330 & $0.020^{*}$ \\
\hline $\begin{array}{l}\text { Quantity and quality of } \\
\text { feedback }\end{array}$ & $3.10(0.63)$ & $3.19(0.69)$ & $-0.090(-0.233,0.055)$ & -1.221 & 0.223 \\
\hline Use of feedback & $3.50(0.70)$ & $3.68(0.77)$ & $-0.183(-0.343,-0.022)$ & -2.239 & $0.026^{*}$ \\
\hline Appropriate assessment & $3.62(0.67)$ & $3.35(0.75)$ & $0.264(0.110,0.419)$ & 3.360 & $0.001 *$ \\
\hline Clear goals and standards & $3.13(0.55)$ & $3.27(0.53)$ & $-0.140(-0.258,-0.021)$ & -2.237 & $0.021 *$ \\
\hline Surface approach & $3.92(0.67)$ & $3.74(0.67)$ & $0.177(0.031,0.323)$ & 2.391 & $0.017^{*}$ \\
\hline Deep approach & $4.08(0.65)$ & $3.96(0.65)$ & $0.118(-0.024,0.260)$ & 1.638 & 0.102 \\
\hline $\begin{array}{l}\text { Learning from the } \\
\text { examination }\end{array}$ & $3.95(0.69)$ & $3.96(0.71)$ & $-0.006(-0.158,0.147)$ & -0.072 & 0.943 \\
\hline Satisfaction & $3.68(0.67)$ & $3.78(0.61)$ & $-0.100(-0.241,0.040)$ & -1.407 & 0.160 \\
\hline
\end{tabular}

a independent t-test, $* p<0.05$

Additionally, the preclinical students tended to put a higher quantity of effort, to learn wider coverage of syllabus and develop a surface approach of learning to meet the assessment demands.

At the end of the questionnaire, the majority of the respondents agreed that the assessment was useful to them. However, about $27 \%$ of the respondents commented that feedback was lacking in the current practice and suggested having more post-assessment feedback sessions with their teachers. The feedback can be provided in the form of written or verbal feedback. The feedback was thought to be important for them to improve on their learning for subsequent assessments. They also believed that the feedback should be given immediately after assessment and ideally with all the teachers involved in teaching the particular course.

Moreover, about a quarter of them also suggested having more problem-based questions testing on clinical applications in assessment. They thought that most of the questions were recall and testing the basic knowledge, as opposed to the application of knowledge and clinical approach. Therefore, they were not able to relate and see the relevance of their learning with the actual clinical practice. The respondents also wished that prolonged time is given for the students to prepare for the examinations. They felt that the time given for revision prior to summative assessment was inadequate for them to prepare, prompting them to become surface learners. They also suggested that a longer interval is given between examinations so that they have ample time to prepare for each examination.

\section{DISCUSSION}

This study observed the influence of assessment on students' learning and their perception of the assessment practice. Generally, UPM medical students tended to develop a deep approach and put great effort into learning. Wu and Jessop have discovered a positive relationship between these two domains, proving assessment as an interconnected environment in which students learn. ${ }^{13}$ This also corresponds to an earlier study in UPM which found that almost $50 \%$ of the medical students adopted a deep approach in their learning. ${ }^{7}$ Interestingly, a previous study has found that the learning approach was correlated with the mode of 
assessment in the program, in which the less formative assessment in a programme, the more it fostered deep approach learning. ${ }^{14}$ Therefore, the UPM MD programme which is dominated by summative assessment may play a role in such finding in the present study. Thus, the students had to put more effort into learning as demanded by their assessment approach since there are major consequences in every examination. Most medical students worldwide usually adopt a deep and strategic approach in their learning. ${ }^{15,16}$ The deep approach of learning is optimal especially in medical education and adopting a surface approach is usually associated with ineffective learning outcomes. ${ }^{17}$

As seen in the comparison between gender, female students tend to develop a surface approach compared to the male which means that female students tend to focus more on memorisation and comprehension rather than thoroughly understanding the knowledge than male. A previous study in China has found that female attitude in learning focused on comprehension and memory and that females paid more attention to learning values than males, ${ }^{18}$ which is also observed in the present study. The positive learning behaviour in females is reflected in their better academic performance than males. ${ }^{5}$ Meanwhile, our study showed that Chinese students tend to put more effort into their learning compared to Malay. They seemed to be more hardworking and learn consistently to achieve good results during the assessment. These may be the reasons why Malay and other ethnicities seem to lag behind the Chinese students. ${ }^{19,20}$ There was also a significant difference between preclinical and clinical students on their learning effort and approach. Preclinical students tend to show higher effort in learning and develop surface approach or learning than clinical students. This is probably because the preclinical curriculum has a lot of summative assessments which emphasise theoretical knowledge. Therefore, these students need to put bigger effort into revision and tend to memorise the knowledge rather than understanding them deeply. The clinical students seemed to be clearer with the goals and expectations of their learning probably because they were able to see the relevance of what they were learning, making it a more meaningful learning experience. They were also divided into smaller groups in class, hence more opportunities to interact with the teachers and engage more in their learning.

However, the students showed the least agreement in the quantity and quality of feedback received. This is similar to the comments made at the end of the questionnaire. The lack of feedback culture is quite common in medical schools worldwide. ${ }^{21-23}$ Also, good quality of feedback must be genuine, personalised, constructive, and non-judgmental in a non-threatening environment. ${ }^{24,25}$ Feedback is important for learners to provide a basis to recognise their deficiencies and to guide for correcting any mistakes. It also helps learners to clarify their learning goals and to have insight into actual performance and consequences. ${ }^{26}$ The reasons can be due to limited time and busy schedules, ${ }^{27}$ lack of training to the feedback provider ${ }^{25}$ and large class size $^{14,23}$ Thus, the awareness of the importance of feedback should be created and provision of training to provide effective feedback to enhance its quality. However, it was observed that the clinical students appreciated the feedback that they received and made use of it compared to preclinical students. It can be because learners value feedback more when they could see its relevance for their clinical practice and thus increasing their motivation to learn.

The preclinical students also suggested having more clinical and problem-based questions in their examinations. As the curriculum is integrated, clinical exposure needs to be concurrently introduced in the preclinical teaching. ${ }^{28}$ Early clinical exposure could familiarise them with the role of basic sciences knowledge in medicine and how to apply the knowledge in clinical settings in the future. ${ }^{29}$ The students also gave feedback on the timeliness of the assessment. Based on a study by Cilliers et al., limited time for assessment tasks will have a negative impact on students' learning. ${ }^{30}$ 'These negative perceptions call for immediate attention from the faculty to identify the improvement for a meaningful learning experience and subsequently enhance students' achievement.

However, there were few limitations observed in this study. The findings from this study do not reflect a generalised influence of the assessment approach on medical students' learning. As the study is crosssectional, the results are also prone to certain biases 
during the period of study. It also cannot be generalised to other medical schools as an assessment approach is certainly unique in each institution. The study indicates the need for further investigations on the effectiveness of the current assessment approach in a wider population in different medical schools and readiness for transformation. This is crucial because, in any assessment approach, it must be kept in mind that a student's learning experience supersedes the attainment of the degree. Therefore, consistent evaluation of the assessment approach shall be done in an institution as a quality assurance to maintain an ideal assessment environment for all stakeholders in the programme.

\section{CONCLUSION}

Female respondents perceived that they practised a surface approach with a better learning attitude compared to males to meet their assessment demand. This study also showed that Chinese students put more effort to prepare for assessment than Malay students. Although feedback is lacking, the clinical students valued more the feedback received and had clearer goals and expectations from their teachers on their work than preclinical students. In contrast, the preclinical students tended to put a higher quantity of effort, to learn wider coverage of syllabus and develop a surface approach of learning to meet their assessment demands. The differences in learning behaviour among different gender and ethnicity are reflected in their academic performance. While the difference between the phase of the study is probably due to the different nature of a preclinical and clinical curriculum that affected their learning. The findings of this study may also support the improvement of current assessment practice to provide a conducive and meaningful learning experience to the students to enhance their academic performance.

\section{CONFLICT OF INTEREST}

The authors declare that there is no conflict of interest regarding the publication of this article.

\section{ACKNOWLEDGEMENT}

The authors would like to acknowledge all respondents for participating in this research.

\section{REFERENCES}

1. Yudkowsky, R., Park, Y.S., \& Downing SM, ed. Assessment in Health Professions Education. 2nd ed. Routledge; 2019.

2. Pereira D, Flores MA, Niklasson L. Assessment revisited: a review of research in Assessment and Evaluation in Higher Education. Assess Eval High Educ. 2016;41(7):1008-1032. doi:10.1080/02602938.2015.1055233

3. Cipra C, Müller-Hilke B. Testing anxiety in undergraduate medical students and its correlation with different learning approaches. PLoS One. 2019;14(3):e0210130. https://doi.org/10.1371/ journal.pone.0210130.

4. Hattingh T, Dison L, Woollacott L. Student learning behaviours around assessments. Australas J Eng Educ. 2019;24(1):14-24. doi:10.1080/22054952.2019.1570641

5. Ismail L. Gender gap in higher education: Perspective on factors influencing enrolment in Malaysian universities: A University of Malaya sample. Online J Qual High Educ. 2015.

6. Veloo A, Krishnasamy HN, Harun HM. What are the learning approaches applied by undergraduate students in English Process Writing based on gender? Int Educ Stud. 2015;8(6):46-55. doi:10.5539/ ies.v8n6p46

7. Zakaria NM, Farok NAJ, Adam SK, Nordin SA. Approaches of learning among medical undergraduates of Faculty of Medicine and Health Sciences, Universiti Putra Malaysia in 2016. Malaysian J Med Heal Sci. 2018;14(1).

8. Wickramasinghe DP, Samarasekera DN. Factors influencing the approaches to studying of preclinical and clinical students and postgraduate trainees. BMC Med Educ. 2011. doi:10.1186/1472-6920-11-22

9. Woolf K, Potts HWW, McManus IC. Ethnicity and academic performance in UK trained doctors and medical students: Systematic review and metaanalysis. BMJ. 2011. doi:10.1136/bmj.d901

10. Vaughan S, Sanders T, Crossley N, O’Neill P, Wass $\mathrm{V}$. Bridging the gap: The roles of social capital and ethnicity in medical student achievement. Med Educ. 2015. doi:10.1111/medu.12597

11. Gibbs G, Simpson C. Measuring the response of students to assessment: the Assessment Experience 
Questionnaire. 11th Improv Student Learn Symp. 2003:1-12.

12. Aday LA, Cornelius LJ. Designing and Conducting Health Surveys: A Comprehensive Guide. Vol 27. 3rd ed. San Francisco: Jossey Bass; 2006. doi:10.5860/ choice.27-5148

13. Wu Q, Jessop T. Formative assessment: missing in action in both research-intensive and teaching focused universities? Assess Eval High Educ. 2018;43 (7):1019-1031. doi:10.1080/02602938.2018.1426097

14. Jessop T, El Hakim Y, Gibbs G. The whole is greater than the sum of its parts: a large-scale study of students' learning in response to different programme assessment patterns. Assess Eval High Educ. 2014;39(1):73-88. doi:10.1080/02602938.2013.792108

15. Chonkar SP, Ha TC, Chu SSH, et al. The predominant learning approaches of medical students. BMC Med Educ. 2018;18(1):1-8. doi:10.1186/s12909-018-1122-5

16. Samarakoon L, Fernando T, Chaturaka R, Senaka R. Learning styles and approaches to learning among medical undergraduates and postgraduates. BMC Med Educ. 2013;13:42. doi:10.1007/s12024012-9392-4

17. Bickerdike A, O’Deasmhunaigh C, O’Flynn S, O’Tuathaigh C. Learning strategies, study habits and social networking activity of undergraduate medical students. Int J Med Educ. 2016;7:230-236. doi:10.5116/ijme.576f.d074

18. Rong L, Rong-Mao L, Kun-Yu L. Do females learn better than males? Gender differences in learning values, abilities, emotions, and behaviours for Chinese undergraduates. J Psychol Res. 2017;7(8):427435. doi:10.17265/2159-5542/2017.08.002

19. Manan AA, Shamsudin S. Comparing Form Four Malay and Chinese students' spoken English. English Teach. 2012;42(1):13-26.

20. Alfan E, Othman N. Undergraduate students' performance: The case of University of Malaya. Qual Assur Educ. 2005;13(4):329-343. doi:10.1108/09684880510626593

21. Ezeala CC, Moleki MM. Evaluation of the educational environments of undergraduate medicine and pharmacy programmes at the University of Zambia. Res Dev Med Educ. 2018;7(1):14-20. doi:10.15171/rdme.2018.004

22. Al-Mously N, Nabil NM, Al-Babtain SA, Fouad
Abbas MA. Undergraduate medical students' perceptions on the quality of feedback received during clinical rotations. Med Teach. 2014;36 (SUPPL.1). doi:10.3109/0142159X.2014.886009

23. Preston R, Gratani M, Owens K, Roche P, Zimanyi M, Malau-Aduli B. Exploring the impact of assessment on medical students' learning. Assess Eval High Educ. 2020;45(1):109-124. doi:10.1080/02602938.2019.1614145

24. Adkoli B.V. The role of feedback and reflection in medical education. SBV J Basic, Clin Appl Heal Sci. 2018;2(1):34-40.

25. Perron N, Louis-Simonet M, Cerutti B, Pfarrwaller E, Sommer J, Nendaz M. The quality of feedback during formative OSCEs depends on the tutors' profile. BMC Med Educ. 2016;16(1):1-8. doi:10.1186/s12909-016-0815-x

26. Krackov S. Giving feedback. In: Dent J, Harden R, eds. A Practical Guide for Medical Teachers. 4th ed. Elsevier; 2013:323-332.

27. Alfehaid LS, Qotineh A, Alsuhebany N, Alharbi S, Almodaimegh $\mathrm{H}$. The perceptions and attitudes of undergraduate healthcare sciences students of feedback: A qualitative study. Heal Prof Educ. 2018;4(3):186-197. doi:10.1016/j.hpe.2018.03.002

28. Atukorala KR, Atapattu P. Pre clinical-basic sciences teaching curriculum of a medical school in a developing country - are we doing it right? J Bangladesh Soc Physiol. 2015;9(2):98-104. doi:10.3329/jbsp.v9i2.22806

29. Mafinejad MK, Mirzazadeh A, Peiman S, et al. Medical students' attitudes towards early clinical exposure in Iran. Int J Med Educ. 2016;7:195-199. doi:10.5116/ijme.5749.78af

30. Cilliers FJ, Schuwirth LW, Adendorff HJ, Herman $\mathrm{N}$, van der Vleuten CP. The mechanism of impact of summative assessment on medical students' learning. Adv Heal Sci Educ. 2010;15(5):695-715. doi:10.1007/s10459-010-9232-9 